\title{
Cooperação Alternativa como Estratégia de Viabilização da Agricultura Familiar 0 Caso da Cooperativa Central Sabor Colonial
}

\author{
Lauri Luiz Kunzler ${ }^{1}$ \\ Rosana Maria Badalotti
}

http://dx.doi.org/10.21527/2237-6453.2017.39.320-352

\begin{abstract}
Resumo
0 processo modernizador que consolidou a Região Oeste de Santa Catarina como polo produtor de commodities alimentares foi, ao mesmo tempo, extremamente rigoroso na seleção dos integrados às cadeias produtivas, o que resultou na exclusão de milhares de agricultores das possibilidades de inserção econômica e reprodução social e em contramovimentos que têm constituído modos alternativos de agregação de valor e cooperação à agricultura familiar. 0 foco do presente estudo é a análise das estratégias de desenvolvimento rural e cooperação para a viabilização da agricultura familiar a partir da atuação da Cooperativa Central Sabor Colonial. A pesquisa caracteriza-se como estudo de caso exploratório descritivo, com abordagem qualitativa. Para a obtenção dos dados, além de pesquisa bibliográfica e documental, foram realizadas entrevistas semiestruturadas com sujeitos representativos da cooperativa analisada, buscando identificar com maior clareza os limites e as possibilidades de suas estratégias de ação. Constatou-se que a referida cooperativa tem atuação mais dedicada à organização do mercado institucional e, como uma possibilidade em potencial, a capacidade ainda pouco explorada de se constituir como referência no crescente mercado de produtos diferenciados provenientes da agricultura familiar. Verificou-se também a necessidade de a cooperativa ampliar sua articulação em redes de comercialização mais amplas, de modo a viabilizar novos espaços de venda para os empreendimentos de atuação local e, com isso, seguir contribuindo na consolidação da cooperação alternativa como estratégia de reprodução da agricultura familiar.
\end{abstract}

Palavras-chave: Desenvolvimento rural. Cooperação alternativa. Agroindústria familiar rural.

\footnotetext{
1 Mestre em Políticas Sociais e Dinâmicas Regionais pela Universidade Comunitária da Região de Chapecó (Unochapecó). Graduado em Administração pela Unochapecó. Administrador na Universidade Federal da Fronteira Sul (UFFS), em Chapecó/SC. lauri.luiz@gmail.com

2 Doutora pelo Programa Interdisciplinar em Ciências Humanas da Universidade Federal de Santa Catarina (UFSC). Mestre em Antropologia Social pela Universidade Federal de Santa Catarina (UFSC). Graduada em Ciências Sociais pela Universidade Federal de Santa Catarina (UFSC). Professora-titular da Universidade Comunitária da Região de Chapecó (Unochapecó). rosana@unochapeco.edu.br
} 


\title{
ALTERNATIVE COOPERATION AS A STRATEGY OF FAMILY FARMING VIABILI- ZATION: THE CASE OF THE COOPERATIVA CENTRAL SABOR COLONIAL
}

\begin{abstract}
The modernizing process that consolidated the region Western Santa Catarina as a hub producer of alimentary commodities was, at the same time, extremely strict in the productive chain staff selection, which resulted in the exclusion of many farmers from the possibilities of economic insertion and social establishment and movements that have formed alternative ways of providing value and cooperation to family farming. This study focuses on the analysis of rural development strategies and cooperation to make the family farming possible through the Cooperativa Central Sabor Colonial intervention. The research is characterized as an exploratory, descriptive study, with a qualitative approach. To obtain the data, besides bibliographic and documental search, semi structured interviews with representative subjects of the cooperative were also performed, seeking a clearer identification of the limits and possibilities of their action strategies. It was able to verify that the above named cooperative dedicates more efforts to the organization of the institutional market and, as a potential possibility, the ability of becoming a reference in the growing differential products market coming from family farming yet little explored. It was also verified that the cooperative has a need of extending its articulation in a wider trading network so as to enable new commercialization spaces to local operation ventures and, thus, continue to contribute for the consolidation of alternative cooperation as a strategy of family farming establishment.
\end{abstract}

Keywords: Rural development. Alternative cooperation. Rural familiar agro industry. 
A agricultura familiar ${ }^{3}$ tem relevante importância na Região Oeste de Santa Catarina e está basilarmente conectada ao seu desenvolvimento. Grandes agroindústrias presentes na região também têm nela suas raízes. O sistema de integração produtor/agroindústria é decorrente do modelo convencional de modernização da agricultura, focado na especialização de atividades e no aumento de escala de produção (MIOR, 2005). A prática, que transformou a realidade regional a partir dos anos 60 e recebeu grande estímulo estatal por meio de políticas e instrumentos de pesquisa e crédito agrícola (PLEIN, 2003), possibilitou a efetiva penetração do capitalismo global na agricultura camponesa local, subordinando-a. ${ }^{4}$ Por outro lado, conforme Campos (1987), com o surgimento do significativo capital agroindustrial e a crescente mercantilização da produção camponesa, os grandes frigoríficos foram paulatinamente fechando as possibilidades de comercialização da produção excedente, atingindo principalmente os produtores não integrados.

Um dos principais indutores do processo modernizador da agricultura brasileira e de sua incorporação ao capitalismo mundial foi o cooperativismo. Regido sob a tutela do Estado, especialmente durante o governo militar, expandiu-se um modelo de cooperativismo empresarial convencional, ${ }^{5}$ de viés capitalista, que sistematicamente subordinou os agricultores, restringindo seu acesso às políticas agrícolas e ao mercado (DUARTE; WERHMANN, 2006) e que fomentou direta e indiretamente os sistemas de integração ajustados para a contínua concentração e intensificação da produção. Consolidou-se assim um processo de verticalização que, conforme Plein (2003), seleciona

3 Lamarche (1993) indica que é possível identificar o conceito de agricultura familiar associando-o ao modo como se dá a exploração da atividade. Para o autor, a exploração familiar corresponde a uma unidade de produção em que propriedade e trabalho estão intimamente ligados à família. Esses fatores são interdependentes e determinam o funcionamento da exploração, a que se submetem também questões mais complexas, como transmissão do patrimônio e reprodução da exploração.

4 Conforme Chayanov (1925 apud ABRAMOVAY, 1998), a integração vertical constitui-se na mais importante forma de penetração do capitalismo na agricultura camponesa. Por meio desse sistema a grande agroindústria aproveita-se da estrutura de unidades de exploração já existente e insere inúmeros estabelecimentos rurais no mercado, mantendo-os subordinados ao seu controle.

5 Utiliza-se neste trabalho a definição de "convencional" para caracterizar o cooperativismo do tipo empresarial/comercial, que é predominantemente alinhado ao sistema hegemônico do capitalismo de mercado e lhe serve de instrumento de penetração no campo e de subordinação dos agricultores ao mercado. 
os produtores financeiramente mais fortes e provoca crescente diferenciação econômica das unidades familiares. Como resultado deste processo, severas consequências têm sido observadas, entre as quais se destacam a exclusão, o endividamento e a descapitalização dos agricultores familiares, a migração para as cidades, principalmente dos jovens rurais, e o consequente envelhecimento do campo.

Pesquisas têm constatado que a atuação das cooperativas convencionais é contraditória a outras formas de cooperação organizadas pelos atores da agricultura familiar na Região Oeste. Ao analisar a proposta de cooperação agrícola da Associação dos Pequenos Produtores do Oeste Catarinense (Apaco), Badalotti (2003, p. 124) afirma que se trata de um modelo de cooperação alternativo que "pretende a construção de um novo modelo de desenvolvimento que se contraponha ao convencional". Nesta direção, experiências inovadoras de cooperação agrícola, desenvolvidas alternativamente ao cooperativismo convencional e protagonizadas principalmente por agricultores excluídos desse sistema, foram desenvolvidas na Região Oeste a partir dos anos $80^{6}$ por movimentos sociais, associações de agricultores e ONGs vinculados à agricultura familiar. As novas formas de cooperação, ${ }^{7}$ mais democráticas, participativas e solidárias, têm o propósito de melhorar a condição social e econômica dos associados. Também mais horizontalizadas e descentralizadas, ${ }^{8}$ essas formas proporcionam o contato direto de produtores e consumidores, possibilitando maior renda aos primeiros e a preservação de uma identidade diferenciada no mercado.

\footnotetext{
6 Originária da tradição camponesa de coletivização de relações de produção e relações sociais (ESTERCÍ, 1984; BONIN, 1987), a cooperação agrícola foi adotada pelos movimentos sociais e ONGs vinculados à agricultura familiar como projeto político e produtivo alternativo ao modelo convencional.

7 Arns (2010) destaca que a cooperação na agricultura familiar pode dar origem a diferentes tipos de organizações, entre as quais se destacam as cooperativas e associações.

8 Levantamento realizado pela Empresa de Pesquisa Agropecuária e Extensão Rural de Santa Catarina (Epagri), no ano de 2010, identificou 70 cooperativas descentralizadas, 70 cooperativas por produto, 30 condomínios e 263 associações de agricultores familiares no Estado de Santa Catarina, agrupando no total 21 mil agricultores (MIOR et al., 2014).
} 
Como alternativa encontrada por muitas famílias para aumentar a renda, têm se constituído atividades relacionadas à agroindústria familiar que visam a transformar produtos primários, como milho, trigo, frutas, leite, carnes, ovos, em produtos com valor agregado, como pães, bolachas, doces, queijos, salames e outros, que, além de associar saberes tradicionais transmitidos de geração em geração, têm possibilitado a produção de alimentos diferenciados, com sabor característico, muito apreciado por consumidores que buscam o deleite em degustar produtos artesanais (MIOR, 2005; DORIGON, 2010). Destacam-se também práticas associativas que visam a um maior rendimento mesmo com pequenos volumes de produção por meio de estratégias coletivas de industrialização e comercialização, especialmente no caso do leite produzido nas pequenas propriedades cooperadas.

No processo de construção de alternativas diante das limitações impostas pela lógica seletiva do modelo convencional de produção agropecuária surgiu, em 2010, a Cooperativa Central Sabor Colonial. Com o objetivo de analisar estratégias de desenvolvimento rural e cooperação para a viabilização da agricultura familiar a partir da atuação dessa organização, foi desenvolvida a pesquisa de Mestrado ${ }^{9}$ que fundamenta esse artigo, visando a compreender o processo de constituição de um modelo alternativo de cooperativismo para a agricultura familiar, caracterizar as estratégias de ação da Cooperativa Central investigada, seus efeitos para as cooperativas e agroindústrias familiares nela inseridas e identificar limitações e potencialidades de sua atuação.

O estudo apresenta-se como de caráter exploratório/descritivo com abordagem qualitativa. Como estratégia geral de pesquisa utilizou-se o Estudo de Caso. O universo da pesquisa é constituído pela Cooperativa Central Sabor Colonial, em toda a sua estrutura orgânica. A Cooper Sabor Colonial, como é denominada, é uma sociedade formada por pequenas cooperativas locais. A sede está localizada em Chapecó/SC e sua área de atuação abrange

9 Dissertação defendida em 2015, no Programa de Pós-Graduação Stricto Sensu em Políticas Sociais e Dinâmicas Regionais da Universidade Comunitária da Região de Chapecó (Unochapecó). 
todo o território catarinense. Suas filiadas são cooperativas de produção e comercialização da agricultura familiar, predominantemente da mesorregião Oeste, formadas e dirigidas por agricultores familiares associados. Atualmente são mais de 3.500 famílias inseridas em 23 cooperativas. Normalmente essas cooperativas locais possuem filiais que representam Agroindústrias Familiares Rurais (AFRs), de propriedade dos associados, cedidas em comodato. ${ }^{10}$ No que se refere a empreendimentos de agregação de valor, são aproximadamente 150 agroindústrias familiares. Os principais tipos de produtos são derivados de leite, derivados de carne suína, panificados, derivados de frutas, hortaliças, derivados da cana-de-açúcar, ovos e mel.

Para atender aos objetivos da pesquisa, delimitou-se como sujeitos a Cooperativa Central, três cooperativas singulares filiadas e seis agroindústrias familiares rurais. Também constituiu sujeito desta pesquisa a Apaco, entidade considerada pelos entrevistados como a genitora da Cooperativa Central. Definidos os sujeitos, foram realizadas visitas para observação e aplicação de entrevistas semiestruturadas. As entrevistas contemplaram temas em torno das estratégias, dificuldades e desafios inerentes à gestão dos empreendimentos e à organização cooperativa, tendo no horizonte os resultados efetivos e os desafios da Sabor Colonial. Foram realizadas 11 entrevistas: 1 com o presidente da Central, $1 \mathrm{com}$ a coordenadora da Apaco, 3 com diretores de cooperativas filiadas e 6 com agricultores familiares que possuem empreendimentos associados.

A etapa de análise e interpretação das informações levantadas considerou as técnicas de Análise de Conteúdo e da Hermenêutica Dialética, buscando compreender criticamente os processos sociais nos quais estão envolvidos os aspectos extradiscursivos que constituem o espaço sociopolítico e econômico, cultural e relacional em que o discurso circula (MINAYO, 2010). Para tanto, em termos analíticos, este artigo busca transversalizar elementos teóricos e empíricos, que permitem compreender a dinâmica

10 Cessão de uso. 
regional em torno do processo de constituição de um modelo alternativo de cooperativismo para a agricultura familiar a partir das estratégias de ação da Cooperativa Central Sabor Colonial.

\section{Processo de Modernização da Agricultura Familiar no Oeste Catarinense}

Nos anos 60 iniciou-se um período de grandes investimentos em todo o país, e o Oeste Catarinense viveu intensamente essa transformação. A produção de suínos, atividade presente na maioria das pequenas propriedades rurais da região, passou a ser visada pelo mercado e recebeu linhas de crédito para fortes incrementos. Já não se tratava de uma produção para a subsistência e para o pequeno comércio local, mas para mercados externos, localizados em outras regiões e Estados. Na mesma lógica, instalou-se a cadeia de produção de aves e transformou-se a bovinocultura de leite (TESTA et al., 2003; PLEIN, 2006). Com esse quadro, estabeleceu-se uma característica regional marcante: a presença de grandes complexos agroindustriais ${ }^{11}$ e cooperativas agropecuárias e seus sistemas de produção integrada, especialmente na cadeia de suínos e aves. ${ }^{12}$

Emblemada na figura da Revolução Verde, a modernização trouxe significativos avanços tecnológicos para a agricultura brasileira, uma vez que significou um processo de ordem nacional, com grande financiamento estatal e substancial investimento da iniciativa privada. Com a proposta de aumentar a produtividade no campo, o próprio Estado atuou fortemente na instituição de políticas conjunturais e estruturais, estimulando a adoção de

\footnotetext{
${ }^{11}$ Segundo Mior (2005, p. 45-46), a noção busca demonstrar a importância econômica do agrobusiness na economia brasileira, “[...] que estaria associada à participação crescente de atividades não estritamente agrícolas ao longo do processo de produção, processamento, industrialização, distribuição e consumo de alimentos".

12 De forma paradoxal, os sistemas de integração têm possibilitado a reprodução social da agricultura familiar. Esta reprodução, entretanto, a partir dos anos 90 têm se caracterizado como cada vez mais dependente dos complexos agroindustriais e grandes cooperativas a partir de uma relação verticalizada e assimétrica entre os agentes situados na cadeia produtiva (MIOR, 2005).
} 
práticas agrícolas inovadoras, como o emprego intensivo de fertilizantes e defensivos e a mecanização das lavouras. Os principais instrumentos foram (i) a pesquisa agropecuária e a extensão rural, para criar tecnologias e levá-las até o agricultor, (ii) o crédito agrícola, para financiar a adoção da tecnologia pelo agricultor, (iii) a política de preços mínimos, garantindo teoricamente um preço adequado para a produção, e (iv) o seguro agrícola, para assegurar o pagamento dos empréstimos (PLEIN, 2006; VIEBRANTZ, 2008).

De acordo com Rover (2009), o processo de modernização da agricultura integrou a Região Oeste Catarinense à política desenvolvimentista nacional, período em que se constituíram cooperativas e agroindústrias de grande porte e se disseminou um sistema capilar de integração entre estas e agricultores familiares, com elevada dependência de crédito subsidiado e de políticas forjadas em escala estadual e federal. O endividamento em prol da modernização agrícola trouxe uma série de efeitos colaterais que levaram a uma profunda crise conjuntural a partir dos anos 80 .

A agricultura familiar na Região Oeste de Santa Catarina passou rapidamente do modo colonial, em que era autônoma, para o formato de integração verticalizada dependente do mercado. Esse processo de mercantilização foi extremamente seletivo, com maior valorização dos produtos voltados à exportação, como as commodities. Ao mesmo tempo, as agroindústrias instaladas na região $0^{13}$ passaram a priorizar a estratégia de concentração da produção e sua intensificação nas propriedades rurais mais estruturadas (PLEIN, 2006). As novas formas de produzir mudaram completamente as relações entre produtores e agroindústrias. Os agricultores, que antes possuíam autonomia na produção de seus animais, passaram a ter de se sujeitar às determinações da indústria: como, quando, quantos e quais animais criar. Apesar da resistência de muitos agricultores, as agroindústrias

13 As primeiras agroindústrias surgiram ainda nos anos 40, com a instalação do Frigorífico Perdigão S.A. em Videira e da S.A. Indústria e Comércio Concórdia (Sadia) em Concórdia. Em seguida, foram instalados frigoríficos em outros municípios da região, como em Chapecó, onde surgiram a S.A. Indústria e Comércio Chapecó e a Cooperativa Central Oeste Catarinense; em Seara, com o Frigorífico Seara; em São Carlos, com o Frigorífico São Carlos e em Itapiranga, com a S.A. Frigorífico Itapiranga (HENN; ALBA, 2008). 
foram impositivas no estabelecimento dos novos padrões de produção. $\mathrm{O}$ não atendimento das regras significava o fim da parceria entre produtor e agroindústria (PAIM, 2006).

A verticalização da produção, sua intensificação e concentração, ${ }^{14}$ provocaram a exclusão de milhares de famílias de pequenos agricultores do sistema produtivo, o que aumentou expressivamente a diferenciação econômica no meio rural. Intensificou-se o êxodo rural e mostrou-se evidente a necessidade de constituição de novas formas de viabilização econômica e reprodução social das famílias de pequenos agricultores na região (TESTA et al., 2003; PLEIN, 2006; BADALOTTI, 2003; BADALOTTI et al., 2007).

\section{Estratégias e Ações Coletivas para a Cooperação na Agricultura Familiar}

O meio rural é um espaço em que se configuram ações que vão além das atividades de produção, constituindo-se em um ambiente institucional permeado por diferenciações sociais e projetos de agricultura distintos, em que se constroem processos de cooperação, resistência e organização política. No Oeste Catarinense a busca por alternativas para a viabilização da agricultura familiar, a partir dos anos 80 , tornou-se um projeto político de agricultores que foram excluídos dos sistemas convencionais de produção e que desejavam construir um novo modelo de agricultura.

A exclusão de muitas famílias de colonos descapitalizados, somada às políticas e estratégias utilizadas pelo governo para submetê-los à hegemonia do sistema desenvolvimentista imposto, levou ao surgimento dos primeiros

\footnotetext{
${ }^{14}$ Segundo Testa et al. (1996, p. 23), em 1980 existiam 67 mil suinocultores na Região Oeste. Em 1995 estimou-se um número de 20 mil, com tendência de concentração ainda maior nos anos seguintes. Em 2008 esse número caiu para 12 mil suinocultores integrados às agroindústrias (ACCS, 2008 apud ANCHAU; ROVER, 2010). Dados da Associação Catarinense de Criadores de Suínos - ACCS (2013) dão conta que há cerca de 8 mil produtores de suínos no Estado, entre integrados e independentes, com a Região Oeste respondendo por mais de $70 \%$ da produção estadual.
} 
movimentos sociais do campo na região, ${ }^{15}$ que aliados aos movimentos de oposição sindical e à atuação da Igreja Católica, se organizaram e desenvolveram uma importante pauta de lutas e reinvindicações. De acordo com Brum (1999), diante do despertar do mundo rural historicamente marginalizado, a Igreja promoveu intensamente a sindicalização rural e o associativismo. Tais movimentos, surgidos em meio ao contexto de sérias crises da agricultura camponesa, contribuíram na mobilização e na criação de alternativas de organização e de geração de renda aos pequenos agricultores e, mais tarde, na criação de políticas públicas específicas (PAIM, 2006).

Scherer-Warren (2001) explica que o associativismo se caracteriza por formas organizadas de ação coletiva, criadas pelos sujeitos sociais em torno de identificações e propostas comuns. Em meio às dificuldades em que se encontravam os pequenos agricultores do Oeste Catarinense na década de 80, excluídos do sistema verticalizado de produção das grandes agroindústrias, o novo associativismo, constituído a partir dos movimentos sociais, tornou-se uma estratégia política na busca de alternativas para a sua permanência no meio rural.

Nesse contexto surgiu também o Movimento de Cooperação Agrícola (MCA) (PRIM, 1996), com a finalidade de oportunizar ferramentas de combate à exclusão social, democratizando e minimizando o "vazio excludente" em que se encontravam os agricultores. De acordo a autora (idem), o MCA no Oeste Catarinense iniciou-se a partir de experiências chamadas de "agricultura de grupo". Essas experiências possuíam grande diversidade e heterogeneidade e diferiam em relação ao número e características das famílias associadas, ao tipo de atividade que coletivizavam (produção,

${ }^{15}$ Os principais movimentos sociais que se constituíram na Região Oeste no período entre 1978 e 1987 foram o Movimento de Oposições Sindicais, o Movimento das Mulheres Agricultoras (MMA), atualmente denominado como MMC (Movimento das Mulheres Camponesas), e o Movimento de Atingidos pelas Barragens do Rio Uruguai (MAB). No que diz respeito ao Movimento Sindical no Oeste Catarinense interessa ressaltar que as orientações deste novo movimento eram basicamente as mesmas do "novo sindicalismo" urbano, que tinham como princípios a autonomia diante do Estado, a organização pelas bases e a construção de uma sociedade democrática e socialista (POLI, 1999, p. 78). 
comercialização, armazenagem), ao tamanho e estrutura da propriedade, ao tempo e período de existência do grupo, à expectativa político-ideológica e à própria forma de se organizar.

Em decorrência das diferentes experiências de cooperação e de mediadores envolvidos no apoio a estas, ${ }^{16}$ surgiram nos anos 90 Organizações Não Governamentais que passaram a assessorar os grupos de agricultores em suas atividades alternativas. Entre os exemplos de organização na região destaca-se a Apaco, criada em $1989,{ }^{17}$ que desde o seu início tem estabelecido parcerias com diferentes atores sociais, o que culminou na constituição de uma Rede de Viabilização da Agricultura Familiar. Por meio desta rede a Associação passou a desenvolver e assessorar projetos e programas voltados à agricultura familiar na Região Oeste com base na cooperação agrícola e práticas agroecológicas (BADALOTTI, 2003).

As novas experiências associativas ocorridas no meio rural a partir desse período tiveram, portanto, o estímulo de atores diretamente envolvidos com os movimentos sociais que se constituíram na região durante os anos 80 e se caracterizavam por grupos de cooperação agrícola e associações voltadas para a compra coletiva de insumos e o cultivo de lavouras comunitárias, bem como a aquisição e o uso coletivo de máquinas e implementos agrícolas. Conforme Badalotti (2003), a partir dos anos 90 foram surgindo também associações coletivas, com o objetivo de compor empreendimentos para se integrar ao sistema das agroindústrias familiares e logo se instalaram as primeiras experiências formais alternativas de agregação de valor por meio da agroindustrialização dos produtos primários locais, práticas que anteriormente eram realizadas de maneira informal.

\footnotetext{
16 Arns (1991 apud ARNS, 2010, p.79) identificou no final dos anos 80 e início dos 90 os seguintes mediadores de apoio à cooperação na Região Oeste: Igreja Católica e Igreja Luterana; Departamento Estadual dos Trabalhadores Rurais (DETR) da Central Única dos Trabalhadores (CUT); Movimento dos Trabalhadores Rurais Sem Terra (MST); Secretaria Agrária do Partido dos Trabalhadores; Associação de Crédito e Assistência Técnica Rural do Estado de Santa Catarina (Acaresc), Apaco e Centro de Estudos e Promoção da Agricultura de Grupo (Cepagro).

17 A Apaco é uma Organização Não Governamental formada e dirigida por grupos de cooperação da Região Oeste catarinense, cujo propósito é estimular e assessorar o desenvolvimento da agricultura de grupo.
} 
A Agroindústria Familiar Rural (AFR) é uma forma de organização em que a família rural produz, processa e/ou transforma parte de sua produção visando, sobretudo, a obter maior valor na comercialização. Mior (2005) afirma que a AFR localiza-se no meio rural, utiliza máquinas e equipamentos de menores escalas, emprega mão de obra e processa matéria-prima da própria unidade ou de vizinhos, remetendo geralmente a um produto artesanal.

Conforme Poli (2006), a agregação de valor à produção primária, obtida por meio da agroindustrialização, constitui-se numa importante alternativa para a permanência de muitas famílias na agricultura mediante sua (re)inserção no processo produtivo, o que a partir da década de 90 passou a reestruturar a dinâmica rural da Região Oeste e passou a ser apoiada por diferentes atores sociais, como é o caso da Unidade Central das Agroindústrias Familiares do Oeste Catarinense (Ucaf), ${ }^{18}$ criada por iniciativa da Apaco em 1999. No mesmo ano, a Secretaria de Desenvolvimento Rural (SDR) do Ministério da Agricultura instituiu o Pronaf Agroindústria, que tinha como objetivo apoiar a formação de conglomerados de agroindústrias familiares. Para dar início a este programa a Secretaria solicitou a elaboração de dois programas-pilotos em SC, entre os quais se destaca o Projeto de Agroindústrias Associativas dos Agricultores Familiares do Oeste Catarinense,${ }^{19}$ que previa apoiar as iniciativas que já vinham sendo desenvolvidas por órgãos públicos, outras instituições e agricultores.

18 Conforme Estatuto Social, a Ucaf é uma base de serviços das Agroindústrias Familiares Rurais do Oeste Catarinense, que se organiza na forma de Associação e se caracteriza como entidade civil sem fins lucrativos. Seu objetivo é prestar serviços para as AFRs nas áreas de comercialização, marketing, controle de qualidade, gestão e contabilidade (UNIDADE..., 2015).

19 O projeto abrangia 23 municípios e previa a instalação de 52 empreendimentos associativos (EPAGRI; DESENVOLVER; APACO 1999 apud MIOR, 2005, p. 166). Para o desenvolvimento do projeto, as redes de agroindústrias deveriam contar com Unidades Centrais de Apoio e Gerência (Ucag) criadas e mantidas pelos próprios agricultores. 


\section{O Protagonismo da Apaco na Organização da Base Associativista das AFRs}

A Apaco é coordenada por agricultores familiares eleitos em assembleia e regida por seu estatuto. Suas atividades são desenvolvidas a partir da contratação de equipe técnica multidisciplinar e da articulação com organizações sindicais, movimentos sociais e órgãos de governo ligados à pesquisa e extensão rural. Como principais objetivos, propõe-se a ser instrumento para a construção de um modelo de agricultura baseado na produção familiar, nos princípios da agroecologia e da cooperação; fomentar, articular, representar e prestar assessoria técnica, política e administrativa aos grupos e organizações de cooperação e contribuir nas estratégias de agregação de valor, comercialização e gestão das unidades de produção familiar e dos grupos de cooperação agrícola. Para atender aos objetivos propostos e como meio de orientar sua atuação, a Apaco desenvolve os seguintes programas: Agroecologia, Agroindústria Familiar, Comercialização Justa, Assessoria Técnica, Gestão Agrícola, Crédito Solidário, Capacitação e Intercâmbio, Desenvolvimento Rural Sustentável e Solidário. O Programa de Agroindústria Familiar tem como objetivo construir alternativas de diversificação das atividades no meio rural para a geração de emprego e renda, visando à melhoria das condições de vida e à permanência das famílias no campo. Seu foco são as pequenas unidades rurais de transformação e agregação de valor dos produtos da agricultura familiar (ASSOCIAÇÃO..., 2015).

Em parceria com outras instituições, e mediante financiamento do Conselho Nacional de Desenvolvimento Científico e Tecnológico (CNPq), a Apaco participou do Programa de Desenvolvimento da Agricultura Familiar Catarinense pela Verticalização da Produção (Desenvolver/SC), ${ }^{20}$ criado em 1998, cujo objetivo foi fomentar a verticalização da produção proveniente

20 Conforme Mior (2005, p. 185), como resultados, após três anos de execução foram instaladas 109 novas agroindústrias familiares rurais associativas, além de mais 32 readequadas, totalizando 141 empreendimentos. Na Região Oeste foram criadas 56 novas agroindústrias e duas foram readequadas. 
da agricultura familiar mediante a criação e consolidação de agroindústrias familiares rurais (DESENVOLVER, 2001). A entidade teve importante atuação na gestão institucional do Programa. Suas ações foram direcionadas efetivamente na criação e na consolidação de agroindústrias familiares rurais. Com as bolsas de fomento tecnológico disponibilizadas pelo CNPq, a equipe técnica multidisciplinar dedicou-se à capacitação das famílias e à elaboração e formalização de projetos de agroindústrias pequenas, adaptadas à realidade local e, portanto, com viabilidade técnica e econômica. A Apaco também foi atuante na pressão junto aos órgãos estatais para a legalização desses empreendimentos, conseguindo a liberação dos registros no Serviço de Inspeção Estadual (SIE). A partir deste programa, essa experiência consolidada serviu de modelo para inúmeras ações e projetos na área de agroindústria familiar no país.

Todas as agroindústrias instaladas na Região Oeste por intermédio da atuação da Apaco associaram-se à Ucaf. Atualmente 105 AFRs estão associadas e todas utilizam a marca Sabor Colonial. A marca surgiu das ações do Programa de Fomento e de Desenvolvimento da Pequena Agroindústria Familiar e Pesqueira - Propagro -, criado no final de 1998 e institucionalizado pela Lei Estadual $n^{\circ} 10.731$. Entre as ações do Programa estavam a concessão de crédito aos agricultores por meio do Fundo de Desenvolvimento Rural e a criação de um selo de qualidade - Sabor Colonial - para as agroindústrias legalizadas (MIOR, 2005). Com o Programa Desenvolver, parte das ações foi retomada e, devido à desativação do Propagro, Apaco e Ucaf assumiram a gestão da marca Sabor Colonial (ASSOCIAÇÃO..., 2015).

A maioria das AFRs associadas à Ucaf são vinculadas a cooperativas de produção e comercialização. ${ }^{21}$ Essas cooperativas têm atuação municipal ou microrregional e são organizadas e geridas pelos próprios agricultores familiares associados. Normalmente, cada AFR constitui uma filial da

21 Atualmente 19 cooperativas locais (singulares) e uma central (Sabor Colonial) estão associadas à Apaco e são usuárias dos serviços da Ucaf (ASSOCIAÇÃ̃..., 2015). 
cooperativa local, o que lhe confere personalidade jurídica e uma série de vantagens decorrentes da possibilidade de negociação com o mercado formal. Nesse caso, a AFR permanece sendo de propriedade dos seus associados, que normalmente são grupos de cooperação formados entre famílias aparentadas ou avizinhadas, e é cedida em comodato à cooperativa. Há também casos de AFRs que não são filiais, mesmo que seus proprietários sejam associados, das cooperativas locais. Entre esses empreendimentos, alguns são constituídos como microempresas, o que é raro, uma vez que antes da Medida Provisória $n^{\circ}$ 619/2013 ${ }^{22}$ ocorria a perda da condição de segurado especial do INSS nesses casos, e outros que não possuem registro de pessoa jurídica, casos em que as atividades comerciais são realizadas individualmente pelo Cadastro de Pessoa Física.

A crescente demanda pelos serviços técnicos fornecidos pela Ucaf, tanto em quantidade quanto em complexidade, exigiu certa descentralização das atividades e a proposição de criação de novas bases de serviços regionais. As organizações envolvidas, todavia, perceberam que essa estratégia limitava sua articulação, tanto em âmbito de cooperativas afiliadas como de entidades parceiras, especialmente quando localizadas em regiões mais distantes (ASSOCIAÇÃO..., 2015). Configurou-se assim a necessidade de criação de uma organização que aglutinasse as diversas experiências e estratégias de mobilização e articulação da agricultura familiar em torno da cooperação, agregação de valor e comercialização no Estado de Santa Catarina.

Diante dessas demandas, os atores passaram a discutir a articulação em redes de comercialização e a formatação e constituição da Cooperativa Central Sabor Colonial. A Assembleia Geral de fundação da cooperativa aconteceu em 2 de agosto de 2010, na cidade de Chapecó.

22 Convertida na Lei $\mathrm{n}^{\circ} 12.873$, de 24/10/2013, estabelece, entre outras providências, a possibilidade de participação do segurado especial em sociedade empresária, em sociedade simples, como empresário individual ou como titular de empresa individual de responsabilidade limitada, de objeto ou âmbito agrícola, agroindustrial ou agroturístico, considerada microempresa, desde que, mantido o exercício de sua atividade rural, a pessoa jurídica componha-se apenas de segurados de igual natureza e esteja sediada no mesmo município ou em município limítrofe àquele em que se desenvolvem suas atividades (BRASIL, 2013). 


\section{Papel da Cooperativa Central Sabor Colonial para a Reprodução Econômica e Social da Agricultura Familiar}

Além de fatores conjunturais que motivam a criação de alternativas de geração de renda e ocupação de mão de obra, as agroindústrias familiares da Região Oeste têm nas redes locais a base do seu enraizamento, na medida em que mobilizam recursos sociais envoltos em relações de parentesco, amizade, confiança, reciprocidade e outras formas de manifestação do capital social (MIOR, 2005). São relações fundamentais tanto para a efetivação de um empreendimento associativo quanto para sua inserção comercial no mercado.

Segundo Radomsky (2006), a maneira como os atores sociais se vinculam e interagem constitui importante elemento para compreender processos de desenvolvimento rural. $\mathrm{O}$ autor afirma que mesmo que as práticas econômicas e sociais tenham passado por um processo de mercantilização, “[...] agricultores têm realizado estratégias de reprodução social que se fundamentam em relações não mercantis” (2006, p. 104). Para o autor, práticas de reciprocidade e relações de proximidade possibilitam a formação de redes sociais orientadas pelas ações de indivíduos e famílias mediante atividades desenvolvidas em "[...] empreendimentos econômicos constituídos por indivíduos ligados por laços de parentesco, amizade e vizinhança” (2006, p. 105), constituindo importantes articulações entre unidades produtivas que formam redes de trabalho, produção e comercialização que buscam assegurar a reprodução econômica e social na agricultura familiar.

Considerando a valorização do comércio local, os produtos coloniais são encontrados com facilidade nos municípios da Região Oeste. A proximidade geográfica aliada às relações sociais e comerciais propicia o abastecimento e consumo de produtos dessa natureza, o que tem caracterizado o que alguns autores denominam "cadeias agroalimentares curtas", ou seja, "[...] formas de comercialização da produção agrícola que buscam proximidade entre produtores e consumidores, possibilitando uma conexão que permita maior interatividade na construção mútua de relações de confiança" (SCARABELOT; SCHNEIDER, 2014, p. 234). 
Estas reflexões nos aproximam em certa medida ao pensamento de Karl Polanyi a partir do seu método de análise institucional que considera "[...] a esfera econômica como parte da totalidade social, cultural e política em que se inscreve historicamente”. Esta afirmação de Polanyi sintetiza sua preocupação e crítica ao pensamento econômico clássico e neoclássico que "[...] identifica o conteúdo da noção de economia com o da noção de mercado" (SCHNEIDER; ESCHER, 2011, p. 188). Neste sentido, o pensamento Polanyiano estimulou um debate entre formalistas e substantivistas no campo da antropologia econômica ao tratar a distinção entre economia formal e substantiva. Considerando que os mercados não são simplesmente uma consequência lógica da relação de oferta e demanda, como defendido no conceito formalista, Polanyi concebe uma visão substantiva segundo a qual os mercados são fruto de construções históricas coletivas. O processo econômico substantivo ocorre pela interação entre os seres humanos com seu entorno e pela institucionalização desse modo de organização social.

A estruturação dos mercados sobre as relações sociais aqui discutidas é muito valiosa para agroindústrias familiares que, sem grandes dispêndios, podem encontrar demanda suficiente para absorver sua produção inicial, entretanto a viabilização das atividades no médio e longo prazos depende da manutenção do equilíbrio financeiro e da capacidade de ampliação do mercado. Como a Região Oeste é constituída majoritariamente por municípios pequenos, a oferta de produtos coloniais tende a ser desproporcional à demanda, que é limitada e seletiva. Limitada considerando o tamanho do mercado local e seletiva levando em conta que somente uma parte desse mercado procura produtos diferenciados.

Com base nesses aspectos, torna-se evidente a necessidade de ampliar o mercado consumidor de produtos das AFRs para além do seu território, buscando centros maiores na região e até mesmo em outras regiões do Estado. É claro que isso varia de produto para produto e, sendo assim, por outro lado, pode haver demanda local de produtos coloniais que não são 
produzidos na região, ou são produzidos em quantidade insuficiente. Nos dois casos, entretanto, comercializar em regiões distantes itens produzidos em pequenas quantidades pode tornar o negócio insustentável por conta dos custos logísticos envolvidos.

Buscar a solução para essa equação foi uma das motivações para a criação da Cooperativa Central Sabor Colonial, conforme explica o seu presidente:

\begin{abstract}
Temos cooperativas e agroindústrias ligadas às cooperativas que têm excedente de produção, [...] localizadas, na maioria das vezes, na nossa região, em pequenos municípios, que têm pouco consumo, e que precisam levar esse produto pra fora. E aí surgiu a necessidade então de discutir uma central, junto com as cooperativas, pra poder fazer esse papel, de fazer essa comercialização pra fora, levar esse produto pra fora, para além das divisas do município, ou da região, pra conseguir comercializar todos os produtos.
\end{abstract}

Note-se a menção feita às cooperativas locais e à necessidade de iniciar a discussão junto a elas. Essas cooperativas representam para os agricultores familiares associados, que desenvolvem atividades junto a agroindústrias de pequeno porte, muito mais que um instrumento de personificação formal e jurídica. Elas desempenham um papel estratégico na organização da produção e da comercialização da agricultura familiar e é por intermédio delas que os agricultores visualizam a possibilidade de viabilização das atividades que desenvolvem e, principalmente, enxergam-se ativos participantes desse processo.

A necessidade de criação de uma cooperativa central, contudo, não surgiu somente das AFRs, tampouco só para elas. Como uma das maiores bacias leiteiras do país, a Região Oeste ${ }^{23}$ possui também um grande

${ }^{23}$ Com 2,147 bilhões de litros em 2013, a Mesorregião Oeste Catarinense é a terceira maior bacia leiteira do país. A segunda é o Triângulo Mineiro/Alto Parnaíba, com 2,335 bilhões de litros, e a maior produtora é a Região Noroeste Rio-Grandense, com 2,995 bilhões de litros (INSTITUTO..., 2013). 
número de pequenos produtores. E assim como acontece nas cadeias de suínos e aves, mas ainda em menor intensidade, nota-se uma tendência em favor do contínuo aumento das escalas de produção também na cadeia do leite. Interessa às grandes empresas concentrar cada vez mais a produção em propriedades selecionadas, com constante aporte tecnológico, visando a obter o maior volume possível de produção pelo menor custo de recolhimento. Aos produtores pequenos e sem condições de investir pesadamente em tecnologia, tanto na melhoria do rebanho como em instalações e equipamentos, a comercialização por meio de cooperativas alternativas caracteriza-se como uma possibilidade para sua permanência na atividade. Para que essas cooperativas alternativas consigam sobreviver em um mercado altamente competitivo, no entanto, são fundamentais as estratégias de comercialização em rede organizadas por meio da Cooperativa Central.

Como produto de uma construção social dos agricultores familiares e suas representações articuladas com diversos atores sociais, a Cooper Sabor Colonial representa a consolidação de diversas iniciativas desenvolvidas ao longo das últimas décadas em termos de cooperação agrícola, associativismo, economia solidária, agroecologia e comercialização regional de produtos com valor agregado da agricultura familiar. Seu propósito é estabelecer e coordenar meios de organizar a produção e impulsionar a comercialização dos produtos da agricultura familiar, de modo a assegurar a viabilidade dos empreendimentos, a sucessão e a reprodução social dos agricultores familiares. 


\section{Atuação no Mercado Institucional de Alimentos}

A Cooperativa Central Sabor Colonial tem destacada atuação no mercado institucional de alimentos, ${ }^{24}$ principalmente no fornecimento para a alimentação escolar. $\mathrm{O}$ acesso ocorre por meio do Programa de Aquisição de Alimentos - PAA ${ }^{25}$ e do Programa Nacional de Alimentação Escolar - Pnae. ${ }^{26}$

O presidente de uma cooperativa filiada à Central, sediada no município de Coronel Freitas, salienta que o mercado institucional é mais estável diante das oscilações de preço e demanda, constituindo um canal importante para a comercialização de produtos dos agricultores associados: "Nosso maior trabalho hoje é na alimentação escolar [...], com os produtos que nós temos lá. E com os produtos que não temos, nós requeremos da Cooperativa Central, né? [sic], que pega de outros municípios e leva lá pra nós”.

A Cooperativa Central permanece atenta às chamadas públicas no Estado de Santa Catarina. Cada novo edital é analisado pela Central em conjunto com a cooperativa filiada do local ou região da chamada, quando houver. Além de avaliar a viabilidade, são verificados os produtos listados no edital que podem ser atendidos pela cooperativa local e aqueles que deverão ser fornecidos pela Central por meio de outras cooperativas do sistema.

24 Em sentido amplo, segundo Maciel (2008), o Mercado Institucional de Alimentos (MIA) refere-se às operações de compra de alimentos realizadas pelas três esferas governamentais, tanto em caráter contínuo para atender, por exemplo, escolas, hospitais e Forças Armadas, quanto em caráter esporádico, como casos de atendimento a calamidades públicas ou mesmo políticas específicas de Estado.

25 O PAA foi criado em 2003, como ação estratégica dentro do Programa Fome Zero, tendo por objetivo básico incentivar a agricultura familiar por meio da compra governamental de produtos alimentares destinados à promoção da segurança alimentar e à formação de estoques públicos estratégicos (SILVA, 2010). O Programa é executado em parceria entre a Companhia Nacional de Abastecimento - Conab, Estados e municípios e conta com recursos dos orçamentos do Ministério do Desenvolvimento Social e Combate à Fome - MDS e do Ministério do Desenvolvimento Agrário - MDA.

26 Embora o Pnae seja uma política pública de aquisição de alimentos bem mais antiga que o PAA, pois teve origem na década de 50, somente nos anos recentes o fortalecimento da agricultura familiar passou a compor seu embasamento legal. O artigo 14 da Lei $n^{\circ} 11.947$, de 16 de junho de 2009, instituiu a garantia de que no mínimo $30 \%$ do total de recursos repassados pelo Fundo Nacional de Desenvolvimento da Educação - FNDE - aos Estados, Distrito Federal, municípios e escolas federais, no âmbito do Pnae, deverão ser utilizados na aquisição de produtos alimentícios da agricultura familiar. Visando à intersetorialidade e à atenção ao fortalecimento da agricultura familiar, as Resoluções do FNDE N ${ }^{\circ} 26$, de 17 de junho de 2013, e N ${ }^{\circ}$, de 2 de abril de 2015, trazem, entre outras disposições, a priorização aos projetos que contenham parâmetros de desenvolvimento local e social. 
Para dar conta das demandas de logística, semanalmente é executado um roteiro Oeste-Litoral-Oeste, intercambiando produtos entre cooperativas filiadas localizadas nas diversas regiões. A mesma sistemática de roteiros de entrega ocorre entre as cooperativas filiadas da Região Oeste, na qual há maior número de empreendimentos, e entre elas e os pontos de entrega previstos nos editais. Os principais produtos atualmente fornecidos pela Sabor Colonial no mercado institucional são: leite, iogurte, queijos, carnes (bovinos, suínos, frangos e peixes/filé de tilápia), suco de uva e maracujá, mel, derivados de cana (açúcar e melado), geleias de frutas, farinha de milho e de trigo integral, maçã, banana, arroz, mandioca, panificados. Todos esses produtos são produzidos por associados de cooperativas filiadas à Cooperativa Central, prevalecendo a prática do ato cooperativo. ${ }^{27}$ Há ainda o fornecimento direto de verduras, hortaliças e ovos pelas cooperativas singulares nos locais das chamadas públicas.

A lógica das rotas de transporte e comercialização é justamente levar produtos de uma região à outra, evitando, sempre que possível, circular com o caminhão vazio. O que uma região produz com maior abundância, podendo gerar excedente, é transportado para uma região mais distante, na qual esse produto não é produzido ou sua produção é escassa. Esta sistemática se justifica pelo fato de cada região do Estado possuir características próprias, tanto por fatores geográficos e de clima quanto por questões culturais e étnicas que possibilitam este tipo de intercâmbio. A diversidade existente em um território mais amplo, como uma mesorregião ou todo um Estado, oportuniza inúmeras possibilidades de intercâmbios de produtos. Esse sistema é certamente uma alternativa relevante para as diversas organizações da agricultura familiar, bem como aquelas da economia solidária.

27 Do Ato Cooperativo: artigo 79. Denominam-se atos cooperativos os praticados entre as cooperativas e seus associados, entre estes e aquelas e pelas cooperativas entre si quando associados, para a consecução dos objetivos sociais. Parágrafo único. O ato cooperativo não implica operação de mercado, nem contrato de compra e venda de produto ou mercadoria. (Lei n ${ }^{\circ} 5.764$, de 16 de dezembro de 1971. Disponível em: http://www.planalto.gov.br/CCivil_03/leis/L5764.htm). 
No formato adotado atualmente pela Cooperativa Central, o custo da logística é encarecido nas entregas ponto a ponto e, conforme informado pelo presidente, esse é o tipo de entrega usual para produtos perecíveis. Entregas de não perecíveis são centralizadas em centros de distribuição que funcionam, em muitos casos, junto as próprias cooperativas filiadas. Os produtos não perecíveis encarecem menos os custos de entrega e, justamente por isso, são mais disputados nas chamadas públicas, inclusive por cooperativas de grande porte que também se habilitam para concorrer nesses editais. Essas cooperativas, todavia, não têm interesse nas entregas ponto a ponto, em que é necessário manter o fornecimento de pequenos volumes, em diversos locais, como escolas, semanalmente, até o final da vigência do contrato.

\section{Atuação no Mercado do Leite}

A Cooperativa Central também atua na organização da produção e comercialização do leite produzido pelos associados das cooperativas filiadas, haja vista que essa atividade está presente na maioria das propriedades e há primordial necessidade de sua viabilização, como destacado pelo seu presidente:

Hoje temos leite no mercado. Foi lançado em maio de 2013, o leite Sabor Colonial, UHT, caixinha. E esse é um desafio de nós viabilizar, porque temos várias cooperativas que têm leite no seu sistema, na sua cooperativa, e nós discutimos a necessidade de a central industrializar esse leite para as cooperativas não ficarem dependentes dos laticínios.

O propósito da Central é constituir um canal de industrialização e comercialização independente da grande indústria, a ser utilizado pelas cooperativas locais, muitas delas fortemente baseadas na atividade leiteira. Dada a maior regularidade e estabilidade no fornecimento e no preço, as chamadas públicas são regularmente acompanhadas pela Sabor Colonial para que pelo menos $1 / 3$ do leite produzido no sistema seja comercializado no 
mercado institucional. O restante é destinado ao varejo, contribuindo para viabilizar a atuação das cooperativas que organizam a produção e, principalmente, o pequeno produtor.

A importância econômica da produção de leite para a pequena propriedade familiar na Região Oeste já foi ressaltada por Testa et al. (2003). Conforme os autores, entre os aspectos positivos da atividade destacam-se o ingresso mensal de receitas nas unidades produtoras, a absorção da mão de obra familiar, especialmente em épocas em que esta estaria ociosa, a capacidade de agregar valor na propriedade, a fácil descentralização de unidades industriais, o grande alcance social e o melhor aproveitamento de terras "não nobres", ou seja, terras de relevo acidentado ou pedregoso, impróprias para o cultivo mecanizado, muito comuns nas pequenas propriedades da região.

Dada a impossibilidade de muitos pequenos agricultores entrarem ou permanecerem em sistemas integrados de produção de aves ou suínos capitaneados pelas grandes agroindústrias, a atividade de produção de leite constitui-se uma alternativa fundamental para a permanência da família no campo, pois possibilita a produção e comercialização em pequena escala e com investimento reduzido. De todo modo, constata-se também nessa atividade uma tendência à concentração da produção e um processo de exclusão dos pequenos produtores pelas grandes empresas, o que se dá por meio da imposição de regulamentos técnicos, da exigência de instalações e equipamentos mínimos e pela acentuada diferenciação no preço pago por volume produzido.

\section{Estratégias de Mercado das AFRs}

As agroindústrias familiares pesquisadas desenvolvem estratégias distintas de comercialização. São mais frequentes o mercado de varejo, principalmente supermercados, e as feiras livres. Cinco das seis AFRs pesquisadas efetuam vendas diretas ao consumidor, especialmente por meio das feiras livres. Outro canal de comercialização bastante utilizado pelas 
agroindústrias pesquisadas é o mercado institucional, coordenado pela Cooperativa Central. Embora com alguma mão de obra contratada de terceiros para as atividades de produção, constatou-se que as principais atividades das AFRs, especialmente vendas e entregas, são majoritariamente executadas por membros das famílias associadas ao empreendimento.

A venda direta ao consumidor é especial para as AFRs. "O dono atendendo o cliente, tem um diferencial!", destacou um agricultor sócio de uma agroindústria de derivados de carne suína localizada no município de Chapecó. É um tipo de relação comercial que se consolida na base da confiança do consumidor, do atendimento personalizado prestado diretamente pelo produtor e na relação social que vem sendo construída ao longo do tempo. Essa relação teve início antes mesmo da formação das AFRs, nos espaços de mobilização social e de discussão de alternativas como resposta ao modelo de exclusão de pequenos agricultores dos sistemas produtivos convencionais.

Os produtos das agroindústrias familiares carregam, principalmente na perspectiva dos consumidores que buscam os canais de venda direta como a feira livre, atributos que os distinguem daqueles encontrados nos supermercados. Ferrari et al. (2014) perceberam, em pesquisa realizada nas feiras livres de Chapecó, que existe a crença dos consumidores numa qualidade intrínseca dos produtos coloniais. Detectaram também o interesse desses consumidores em fortalecer um mercado que se diferencia do varejo corporativo, que valoriza a pequena produção local e reconecta o produtor e o consumidor. Conforme os autores, a feira livre, enquanto mercado de vendas diretas com relações face a face, se constitui uma estratégia alternativa àquelas do sistema agroalimentar convencional e possibilita a realização e o fortalecimento de conexões sociais enraizadas em valores locais, culturais, sociais e morais.

Embora vendam parte de sua produção para supermercados, é nas vendas diretas que as AFRs percebem melhores ganhos financeiros. A viabilidade econômica dos empreendimentos só é atingida trabalhando com preços diferenciados para produtos de qualidade superior. Ou seja, dificil- 
mente uma AFR se viabilizará se disputar mercado por preço. Por outro lado, a ampliação das vendas diretas ao consumidor requer um esforço maior das AFRs, principalmente ao agirem individualmente. Na Região Oeste há grande oferta de produtos coloniais, despertando assim o interesse pela expansão para novos mercados, em regiões mais distantes e mais populosas. A dificuldade, no entanto, reside nas grandes distâncias desses mercados, o que demandaria estruturas de venda, cobrança e logística.

Apesar da provável demanda por produtos das agroindústrias familiares nos mercados mais distantes, dificilmente uma AFR isoladamente atingiria a capacidade de atendê-la. Tanto no que se refere à manutenção das estruturas necessárias para a logística quanto para o suprimento dos volumes de produtos que seriam demandados nesses novos mercados. Há, contudo, que se avaliar a possibilidade de expansão no mercado local, considerando o potencial de atingir um leque mais amplo de consumidores. Ambas as possibilidades dependem necessariamente, da intervenção da Cooperativa Central, seja na configuração de redes logísticas mais longas, seja na criação de campanhas que incentivem o consumo de produtos diferenciados nos mercados locais.

\section{Enfatizando os Diferenciais da Cooperação Alternativa}

Um dos principais diferenciais da cooperação alternativa é transformar a realidade do agricultor familiar, em que este é o principal agente da mudança, quebrando paradigmas e desenvolvendo aprendizagem e disposição para o associativismo e o cooperativismo. Ressalte-se o perfil endógeno da mudança de realidade e a importância das entidades e organizações surgidas no âmbito da agricultura familiar para assessorar o processo, formando assim um sistema diferenciado, estruturado por um capital social de diferentes trajetórias constituídas pela agricultura familiar da região, tendo em vista um novo modelo de desenvolvimento rural. 
Desenvolvimento, segundo Inayatullah (1967 apud MOEMEKA, 1989), é um processo por meio do qual uma sociedade consegue maior controle sobre o meio e sobre o seu próprio destino político, além de capacitar seus indivíduos a obter maior controle sobre si mesmos. A autonomia, portanto, representa um elemento-chave para o desenvolvimento.

Citando Ploeg et al. (2000, p. 395-396), Schneider afirma que o desenvolvimento rural seria uma tentativa de reconstrução das bases econômicas, sociais e ambientais, e das próprias unidades familiares, diante das limitações e lacunas intrínsecas do paradigma produtivista. Nesta direção, "[...] o desenvolvimento rural representaria uma possibilidade de ir além da modernização técnico-produtiva, apresentando-se como uma estratégia de sobrevivência desenvolvida por unidades familiares rurais" que mediante estratégias e mecanismos produtivos e institucionais alternativos encontram possibilidades de garantir sua reprodução (SCHNEIDER, 2004, p. 96-97).

Entre os fatores que distinguem do modelo convencional a cooperação alternativa, enfatizados por aqueles que a vivem e constroem, estão a autonomia, a participação ativa, a democracia, o respeito às opiniões de todos e disposição para o aprendizado. Ao contrário das cooperativas convencionais, tanto a Cooperativa Central quanto as afiliadas operam na perspectiva de efetivamente fortalecer os agricultores associados incentivando a descentralização do processo de industrialização e agregação de valor à produção.

As cooperativas alternativas são efetivamente geridas pelos associados. A participação atuante de todos confere maior rigidez no cumprimento dos valores e princípios do cooperativismo. Além das questões econômicas, essas organizações têm como propósito construir o conhecimento coletivo, com formação, capacitação e gestão participativa, para tornar o sistema mais democrático. 
Embora em sua atuação existam limitações e normalmente ocorram situações em que são necessários ajustes, como um processo contínuo de construção social, o modelo alternativo de cooperação configura-se como possibilidade mais concreta de valorização e reprodução social da agricultura familiar e de desenvolvimento rural.

\section{Considerações Finais}

O caso analisado ao longo desta pesquisa emerge de um processo de construção histórica no qual gravitam experiências que podem ser consideradas bem-sucedidas, embora tragam em seu bojo uma série de desafios. Podem ser consideradas dessa forma porque têm resistido às dificuldades inerentes a um contexto geral fundamentalmente muito difícil para movimentos contra-hegemônicos e se reinventado. Como construção social em contínua edificação, há limites e possibilidades a serem considerados, uma vez que podem influenciar a trajetória de organizações como a Cooperativa Central Sabor Colonial e sua base associativa.

A resposta de um agricultor, sócio de AFR, perguntado sobre o principal desafio a ser enfrentado, é emblemática para trazer às considerações finais deste artigo: "A mentalidade do agricultor, de não ser somente produtor". Ou seja, é fundamental que os agricultores, além de buscarem a capacitação necessária para suas atividades produtivas, busquem formação e aprendizado para participarem ativamente de movimentos mais amplos, que vão além dos limites de suas propriedades. Uma formação empreendedora e inovadora, além de ser muito positiva para as atividades desenvolvidas pela agroindústria familiar, é altamente contributiva para as cooperativas e outras organizações das quais os agricultores participem. As organizações sozinhas, como atores constituídos, mas sem a participação de todos os sujeitos envolvidos, tornam-se vulneráveis, como reforça a presidente de uma cooperativa sediada no município de Chapecó, filiada à Central: "Os agricultores têm que se sentir parte da organização. É o despertar do senso crítico. O agricultor tem que se sentir parte: ele faz, ele constrói, e não os outros". 
Neste sentido, cabe às organizações e cooperativas trabalharem projetos de formação para o médio e longo prazos, que podem construídos por meio de parcerias com outros atores sociais, como sindicatos, institutos de pesquisa e universidades. Iniciativas dessa natureza podem compor a solução de um dos grandes gargalos identificado na pesquisa de campo, que é a carência de mão de obra para as agroindústrias familiares rurais. Essa questão tem relação direta com outro grande desafio, reiteradamente manifestado nas entrevistas, que é a sucessão familiar. "[...] nós precisamos discutir soberania alimentar e quem que são os que vão produzir alimentos no futuro, pros nossos filhos, pros nossos netos. Quem que vai ser?” destaca o presidente da Cooperativa Central. A preocupação abrange as agroindústrias familiares e seus associados, bem como as propriedades indiretamente vinculadas por meio do fornecimento de matéria prima às AFRS. Em sentido amplo, a questão sucessória inquieta também as próprias comunidades rurais e as organizações da agricultura familiar, como as pequenas cooperativas. "Eu acho que isso deixa a gente um pouco assustado. Daqui a dez, quinze, vinte anos, quem que vai tocar essas organizações que a gente tem? Vamos ter sucessor que toca isso?”, pergunta-se um agricultor do município de Seara, sócio de uma agroindústria de derivados de leite.

O mercado move-se na tendência de valorização dos produtos diferenciados, especialmente os orgânicos e aqueles com atributos de artesanal ou colonial. Além de um criterioso acompanhamento técnico dos processos de produção, inclusive das matérias-primas utilizadas pelas agroindústrias familiares, o que pode ser executado pelas cooperativas filiadas, é necessário que a Central construa uma identificação forte da marca Sabor Colonial com atributos de qualidade superior e diferenciada, atingidos apenas a nível de produção em pequena escala, como é característico de sua base associativa.

A consolidação de redes estruturadas de comercialização pode significar o atendimento da regularidade exigida pelo mercado, pois supera uma série de limitações inerentes à atuação isolada de pequenas cooperativas locais, dada sua exposição e vulnerabilidade a fatores climáticos, políticos 
e econômicos regionais. Embora com suas qualificações, e dadas suas limitações atuais, acredita-se que seja fundamental a inserção da Cooperativa Central em estratégias mais amplas, a serem articuladas conjuntamente com outros atores. Certamente a atuação conjunta em determinadas estratégias confere maiores possibilidades para a superação dos limites e, inclusive, maior peso para a representação em questões que envolvem políticas públicas e a ação dos governos. Assim sendo, para ser vanguarda e proativa em sua área de atuação, tanto para detectar mudanças conjunturais, como regulamentação (sanitária, fiscal, tributária), crédito e políticas públicas, quanto de mercado, como tendências de consumo, potenciais riscos e oportunidades, a Cooperativa Central Sabor Colonial não pode atuar isoladamente. Ao mesmo tempo em que precisa ter um olhar para dentro da organização, sob os critérios da eficiência administrativa, a gestão da cooperativa necessita exercer uma visão holística e dialogar permanentemente com outros atores para construir e aprimorar parcerias estratégicas.

A presente pesquisa possibilitou conhecer e analisar estratégias, limites e possibilidades de atuação da Cooperativa Central Sabor Colonial na viabilização da agricultura familiar. Por outro lado, a investigação suscita novas provocações para futuros estudos que possam incluir como sujeitos de pesquisa agricultores associados às cooperativas locais que desenvolvem outras atividades de agregação de valor, não vinculadas às AFRs, para examinar possíveis avanços obtidos com a criação da cooperativa central. Oferece também elementos para analisar outros casos em que os mercados institucionais têm sido importante estratégia de viabilização da agricultura familiar na Região Oeste e em outras regiões do país.

\section{Referências}

ABRAMOVAY, R. O admirável mundo novo de Alexander Chayanov. Estudos Avançados, v. 12, n. 32, p. 69-74, 1998. Disponível em: <http://www.scielo.br/scielo. php?script=sci_arttext $\&$ pid=S0103-40141998000100006 $>$. Acesso em: 13 mar. 2015. 
ANSCHAU, C. T.; ROVER, O. J. Impactos de redes cooperativas de produção de leite na reconfiguração de um território predominantemente rural. CONGRESO LATINOAMERICANO DE SOCIOLOGÍA RURAL. Porto de Galinhas, 2010. Disponível em: <http://www.alasru.org/wp-content/uploads/2011/09/GT17-Cleusa-Teresinha-Anschau.pdf> Acesso em: 7 set. 2015.

ARNS, C. E. A cooperação na agricultura familiar no Território Alto Uruguai Catarinense (SC) Brasil. 2010. Dissertação (Mestrado em Desenvolvimento Regional) - Universidade de Santa Cruz do Sul, Santa Cruz do Sul, 2010.

ASSOCIAÇÃO CATARINENSE DE CRIADORES DE SUÍNOS (ACCS). Relatório anual 2013. Disponível em: <http://www.accs.org.br/arquivos_internos/index.php>. Acesso em: 17 jul. 2015.

ASSOCIAÇÃO DOS PEQUENOS AGRICULTORES DO OESTE CATARINENSE (Apaco). Pesquisa documental. Chapecó, 2015.

BADALOTTI, R. M. A cooperação agrícola e a agroecologia como base para a viabilização da agricultura familiar no oeste catarinense: o papel da Apaco (Associação dos Pequenos Agricultores do Oeste Catarinense) e demais agentes sociais. 2003. Tese (Doutorado em Ciências Humanas) - Universidade Federal de Santa Catarina, Florianópolis, 2003.

BADALOTTI, R. M. et al. Reprodução social da agricultura familiar e juventude rural no Oeste Catarinense. Artigo apresentado ao VII RAM - UFRGS, Porto Alegre, Brasil, 2007. Disponível em <http://www.emdialogo.uff.br/sites/default/files/Rosana_Badalotti_et_alli.pdf>. Acesso em: 26. jun. 2013.

BONIN, A. et al. Luta pela terra e contradições de um projeto comunitário de vida. In: BONIN, A. et al. Movimentos sociais no campo. Curitiba: Criar; Scientia et Labor, 1987.

BRASIL. Lei $n^{\circ}$ 5.764, de 16 de dezembro de 1971. Define a Política Nacional de Cooperativismo, institui o regime jurídico das sociedades cooperativas, e dá outras providências. Disponível em: <http://www.planalto.gov.br/CCIVIL_03/leis/L5764. htm>. Acesso em: 12 dez. 2014.

Lei $n^{\circ} 12.873$, de 24 de outubro de 2013. Altera as Leis $\mathrm{n}^{\mathrm{os}} 8.212$, de 24 de julho de 1991, e 8.213, de 24 de julho de 1991, o Decreto-Lei ${ }^{\circ} 5.452$, de $1^{\circ}$ de maio de 1942 - Consolidação das Leis do Trabalho, as Leis ${ }^{\text {os }} 11.491$, de 20 de junho de 2007, e 12.512, de 14 de outubro de 2011, e dá outras providências. Disponível em: <http://www.planalto.gov.br/ccivil_03/_ato2011-2014/2013/Lei/L12873.htm>. Acesso em: 13 jul. 2015. 
BRUM, A. J. O desenvolvimento econômico brasileiro. Ijuí: Ed. Unijuí, 1999.

CAMPOS, I. Os colonos do Rio Uruguai: relações entre a pequena produção e agroindústrias no Oeste Catarinense. 1987. (Dissertação) - Universidade Federal da Paraíba, 1987.

DESENVOLVER. Folder com os primeiros resultados. Florianópolis: Governo de Santa Catarina, 2001.

DORIGON, C. O mercado informal dos produtos coloniais da Região Oeste de Santa Catarina. In: ENEG - ENCONTRO NACIONAL DE ESTUDOS DO CONSUMO, 5., ENCONTRO LUSO-BRASILEIRO DE ESTUDOS DO CONSUMO, 1., set. 2010, Rio de Janeiro. Disponível em: <http://estudosdoconsumo.com.br/wp-content/ uploads/2010/09/1.3-_Clovis_Dorigon1.pdf>. Acesso em: 10 nov. 2013.

DUARTE, L. M. G.; WEHRMANN, M. E. S. F. Histórico do cooperativismo no Brasil e perspectivas para a agricultura familiar. In: SABOURIN, E. (Org.). Associativismo, cooperativismo e economia solidária no meio rural. Brasília, UnB: 2006. p. 13-28.

ESTERCI, N. Roças comunitárias: Projetos de transformação e formas de luta. In: ESTERCI, N. (Org.). Cooperativismo e coletivização no campo: questões sobre a prática da Igreja popular no Brasil. Rio de Janeiro: Ed. Marco Zero, 1984.

FERRARI, D. L. et al. Agroindústrias familiares: estratégias e desafios da inserção mercantil em Santa Catarina. In: ESTEVAM, D.; MIOR, L. C. Inovações na agricultura familiar - as cooperativas descentralizadas em Santa Catarina. Florianópolis: Insular, 2014.

HENN, C. G.; ALBA, R. S. O processo de crise da Chapecó alimentos: implicações sócio- territoriais no contexto local e regional. ENCONTRO INTERNACIONAL DE GEOGRAFIA: TRADIÇÕES E PERSPECTIVAS. 2008, São Paulo. Anais... São Paulo, $1^{\circ}$-5 dez. 2008.

INSTITUTO BRASILEIRO DE GEOGRAFIA E ESTATÍSTICA (IBGE). Pesquisa pecuária municipal-2013. Disponível em: <http://www.sidra.ibge. gov.br>. Acesso em: 17. jan. 2015.

LAMARCHE, H. (Coord). Agricultura familiar. Uma realidade multiforme. Campinas: Editora da Unicamp, 1993. Vol. I.

MACIEL, L. R. Mercado institucional de alimentos: potencialidades e limites para a agricultura familiar. 2008. Dissertação (Mestrado em Agronegócios) - Faculdade de Agronomia e Medicina Veterinária da Universidade de Brasília, Brasília, DF, 2008. 
MINAYO, M. C. S. O desafio do conhecimento - pesquisa qualitativa em saúde. 12. ed. São Paulo: Hucitec, 2010.

MIOR, L. C. Agricultores familiares, agroindústrias e redes de desenvolvimento rural. Chapecó: Argos, 2005.

MIOR, L. C. et al. Inovações organizacionais da agricultura familiar no Sul catarinense. In: ESTEVAM, D.; MIOR, L. C. (Org.). Inovações na agricultura familiar: as cooperativas descentralizadas em Santa Catarina. Florianópolis: Insular, 2014.

MOEMEKA, A. Perspectives on development communication. Communatio Socialis Yearbook, v. 8, p. 47-68, 1989.

PAIM, E. A. Aspectos da constituição histórica da região Oeste de Santa Catarina. Saeculum - Revista de História. João Pessoa, jan./jun. 2006. Disponível em <http:// periodicos.ufpb.br/ojs/index.php/srh/article/view/11346>. Acesso em: 10. nov. 2013. PLEIN, C. As metamorfoses da agricultura familiar: o caso do município de Iporã d'Oeste, Santa Catarina. 2003. Dissertação (Mestrado) - UFRGS, Porto Alegre, 2003.

. A modernização da agricultura brasileira e seus efeitos sobre a agricultura familiar no oeste catarinense. In: Revista Faz Ciência, Unioeste, vol. 8, n. 1, p. 35-72, 2006.

POLI, O. L. Leituras em movimentos sociais. Chapecó: Editora Grifos, 1999.

. Economia solidária e a formação humana: experiências de trabalho e educação em agroindústrias familiares associativas no oeste catarinense. 2006. Tese (Doutorado em Educação) - Universidade de Campinas, Campinas, 2006.

PRIM, L. Agricultura de grupo e projeto camponês: avanços e limites na construção da cidadania - o movimento de cooperação agrícola no oeste catarinense. 1996. Florianópolis, Dissertação (Mestrado em Sociologia Política) - UFSC, 1996.

RADOMSKY, G. F. W. Reciprocidade, redes sociais e desenvolvimento rural. In: SCHNEIDER, S. (Org.). A diversidade da agricultura familiar. Porto Alegre: Editora da UFRGS, 2006. p. 104-133.

ROVER, O. J. Gestão política e desenvolvimento no Oeste de Santa Catarina. Cadernos do Ceom, ano 22, n. 30, 2009.

SCARBELOT, M.; SCHNEIDER. S. As cadeias agroalimentares curtas e desenvolvimento local - um estudo de caso no município de Nova Veneza/SC. In: ESTEVAM, D.; MIOR, L. C. Inovações na agricultura familiar - as cooperativas descentralizadas em Santa Catarina. Florianópolis: Insular, 2014. 
SCHERER-WARREN, I. Movimentos sociais e participação. In: SORRENTINO, Marcos. (Coord.). Ambientalismo e participação na contemporaneidade. São Paulo: Educ; Fapesp, 2001.

SCHNEIDER, S. A abordagem territorial do desenvolvimento rural e suas articulações externas. Sociologias, Porto Alegre, n. 11, p. 88-125, jun. 2004.

SCHNEIDER, S.; ESCHER, F. A contribuição de Karl Polanyi para a sociologia do desenvolvimento rural. In: Sociologias, Porto Alegre, ano 13, n. 27, p. 180-219, maio/ago. 2011.

SILVA, J. G. Fome zero: a experiência brasileira. Brasília: MDA, 2010.

TESTA, V. M. et al. O desenvolvimento sustentável do Oeste Catarinense: proposta para discussão. Florianópolis: Epagri, 1996.

. A escolha da trajetória da produção de leite como estratégia de desenvolvimento do Oeste Catarinense. Florianópolis: Epagri, 2003.

UNIDADE CENTRAL DAS AGROINDÚSTRIAS FAMILIARES (Ucaf). Pesquisa documental, 2015.

VIEBRANTZ, K. P. M. A extensão rural: ambiente, agricultura e associativismo. Revista Grifos, Unochapecó, n. 25, dez. 2008.

Recebido em: 6/11/2015

Aceito em: 19/8/2016 